\title{
Evaluating catchment-scale hydrological modeling by means of terrestrial gravity observations
}

\author{
Shaakeel Hasan, ${ }^{1}$ Peter A. Troch, ${ }^{2}$ Patrick W. Bogaart, ${ }^{1}$ and Corinna Kroner ${ }^{3}$ \\ Received 5 July 2007; revised 8 January 2008; accepted 1 April 2008; published 9 August 2008.
}

[1] In a previous study (Hasan et al., 2006) we applied time series analysis and distributed hydrological modeling techniques to investigate the effect of hydrological processes on observed terrestrial gravity residuals. In this study we apply terrestrial gravity observations (measured in one location) to constrain simple hydrological models in a catchment around the gravimeter. A superconducting gravimeter observes with high frequency $(1 \mathrm{~Hz})$ the temporal variations in the gravity field with high accuracy (sub $\mathrm{nm} \mathrm{s}^{-2}$ for hourly variation) near Moxa, Germany since 1999. Hourly gravity residuals are derived by filtering and reducing for Earth tides, polar motion, barometric pressure variations, and instrumental drift. These gravity residuals show significant response to hydrological processes (precipitation, evaporation, surface and subsurface flow) in the catchment surrounding the observatory. We can thus consider the observed gravity change as an integrator of catchment-scale hydrological response (similar in nature as discharge measurements), and therefore use it to constrain catchment-scale hydrologic models. We test a set of simple water balance models against measured discharge, and employ observed gravity residuals to evaluate model parameters. Results indicate that a lumped water balance model for unsaturated storage and fluxes, coupled with a semidistributed hydraulic groundwater model for saturated storage and fluxes, successfully reproduces both gravity and discharge dynamics.

Citation: Hasan, S., P. A. Troch, P. W. Bogaart, and C. Kroner (2008), Evaluating catchment-scale hydrological modeling by means of terrestrial gravity observations, Water Resour. Res., 44, W08416, doi:10.1029/2007WR006321.

\section{Introduction}

[2] The central problem in catchment hydrology is to accurately measure and model atmospheric forcing and hydrologic partitioning at large spatial scales. The issue is complicated as most observations of hydro-meteorological fluxes (e.g., precipitation, evaporation) and subsurface storage (e.g., soil moisture, phreatic groundwater level) are available only at the point-scale. Landscape heterogeneity (topography, soils, vegetation) and space-time variability of atmospheric forcing prevent simple upscaling to catchment relevant stores and fluxes. However, much progress has been made recently using remotely sensed information to develop spatial estimation methods for precipitation [e.g., Krajewski et al., 2006; Bales et al., 2006], evaporation [e.g., Bastiaanssen et al., 1997; Su, 2002], soil moisture [e.g., Su et al., 1997; Verhoest et al., 1998; Njoku and Li, 1999; Jackson et al., 1999], streamflow [e.g., Alsdorf and Lettenmaier, 2003], and terrestrial water storage [e.g., Rodell and Famiglietti, 1999, 2001, 2002]. Application of several of these advanced observation methods to smaller catchments (hereafter defined as the intermediate scale: $10^{0}$ to $10^{1} \mathrm{~km}^{2}$ )

\footnotetext{
${ }^{1}$ Hydrology and Quantitative Water Management Group, Wageningen University, Netherlands.

${ }^{2}$ Department of Hydrology and Water Resources, University of Arizona, Tucson, Arizona, USA.

${ }^{3}$ Institute of GeoSciences, Friedrich-Schiller-University, Jena, Germany.

Copyright 2008 by the American Geophysical Union. 0043-1397/08/2007WR006321\$09.00
}

is difficult due to spatial and temporal resolution limits of the required satellite data. Developments of geophysical measurement techniques (e.g., ground penetrating radar, electrical resistivity tomography, electromagnetic induction) pave the way toward progress in observing hydrologic state variables and fluxes at this intermediate catchment-scale.

[3] Recent progress in accurately monitoring temporal gravity variations by means of superconducting gravimeters and satellite gravimetry brought a complete new avenue of estimating water balance components. Temporal variations of the Earth's gravity field are caused by a variety of complex geophysical phenomena including lunar-solar tides, postglacial rebound, atmospheric and oceanic mass redistribution, and hydrology [Chao, 1994]. Superconducting gravimeters (SG), providing $\mathrm{nm} \mathrm{s}^{-2}$ accuracy in shortterm (e.g., hourly) gravity changes and long-term stability, are suitable devices to monitor temporal gravity variation with high accuracy [Goodkind, 1999]. The Global Geodynamics Project (GGP) [Crossley et al., 1999] began in 1997 with one of the purposes to record the Earth's gravity field with extremely high accuracy (temporal variation with an accuracy of $\sim 10^{-9} \mathrm{~m} \mathrm{~s}^{-2}$ ) at a number of stations around the world using superconducting gravimeters. In this study we use data from the Geodynamic Observatory Moxa (one of the GGP stations), Germany.

[4] It is estimated that hydro-meteorological variations (e.g., water storage, atmospheric pressure) can cause $\sim 5$ to $100 \mathrm{~nm} \mathrm{~s}^{-2}$ changes in gravity at a daily to yearly timescale [Torge, 1989]. Several studies have investigated empirical relationships between hydrometeorological and gravity data 
[Mäkinen and Tattari, 1988; Peter et al., 1995; Bower and Courtier, 1998; Crossley and Xu, 1998; Kroner, 2001; Harnisch and Harnisch, 2002; Van Camp et al., 2006]. Very few studies have used hydrological modeling to explain local, regional and continental hydrological effects on gravity [Hasan et al., 2006; Van Camp et al., 2006; Hinderer et al., 2006]. Pool and Eychaner [1995] and Pool [2005] show that temporal variations in gravity, determined by repeated gravity surveys, can be used to estimate aquifer storage change.

[5] In a previous study [Hasan et al., 2006] we applied time series analysis and distributed hydrological modeling techniques to understand the effect of the hydrological processes on observed gravity residuals at Moxa, Germany. Time series modeling provided us with a simple yet effective technique to correct for precipitation effects on short-term (hourly to daily) gravity residuals. Analysis of groundwater and gravity residuals demonstrated different dynamics present in the catchment at longer timescales (months). Distributed water balance modeling explained both short and long-term behavior of the gravity signal and confirmed the findings from the time series analysis. In this study we investigate how observed gravity residuals can aid catchment-scale hydrological modeling. Considering gravity observations as an integrator of catchment-scale hydrological response (similar in nature as discharge measurements), we use gravity variation data to constrain hydrological models of the catchment. We use a simple lumped water balance model to model soil moisture and snow storage change and a semidistributed hydraulic groundwater model [Troch et al., 2003] to model hydrological processes in the catchment. The temporal change in gravity is calculated using the distributed storage information of different components. To calibrate the models we used both discharge and gravity data.

\section{Study Area and Data}

[6] The Silberleite catchment is situated in the Federal state of Thuringia in Germany (Figure 1). The catchment, located in the Silberleite valley, is at the border of the Thuringian slate mountains. Having stable bed rock and other necessary environmental conditions for installation of sensitive geophysical instruments [Teupser, 1975], the valley hosts the Geodynamic Observatory Moxa (one of the German GGP stations).

[7] The observatory is situated in a spruce forest and the surrounding mountains consist of intensively folded and fractured basement rocks. In the surroundings of the station thick series of slates and graywackes of Paleozoic (lower and upper Visean) Age are found. The elevation in the catchment varies between 425 and $535 \mathrm{~m}+\mathrm{MSL}$. The hillslopes present in the catchment are of various shapes, gradients and characteristics. Field investigations show the presence of many preferential flow paths under the soil cover caused by secondary porosity in folded and fractured bed rock. The Silberleite valley at the observatory is a second Strahler order catchment with intermittent and ephemeral streams. The main runoff generation processes are saturation excess runoff in the riparian zone and rapid snowmelt. The soil layer (including the weathering layer) has mostly a depth between 0.4 and $1 \mathrm{~m}$.

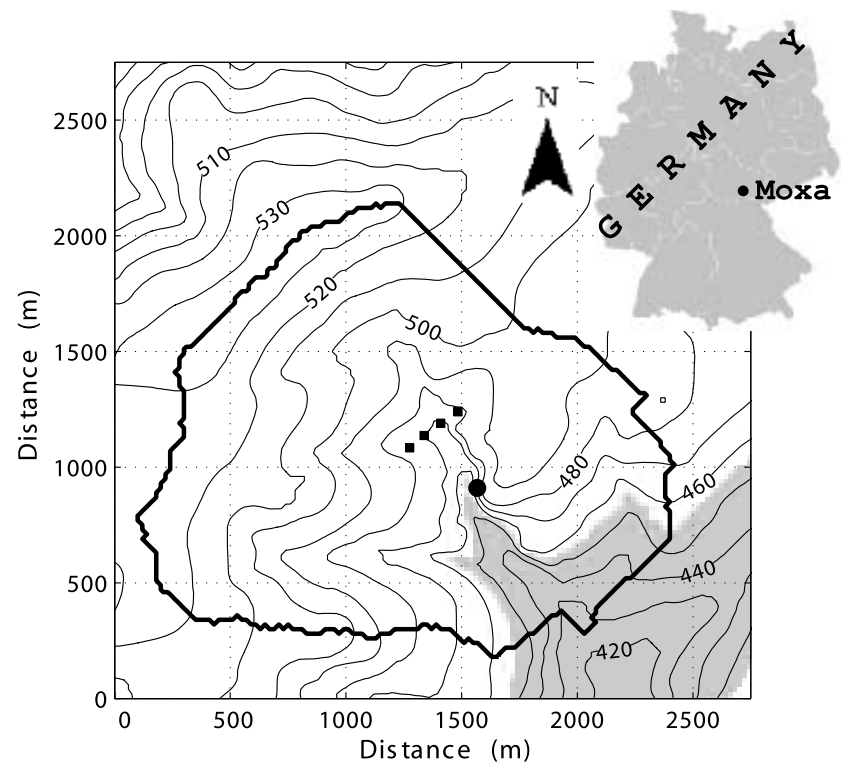

Figure 1. Location (top-right) and topography (distances are in $\mathrm{m}$, elevations are in $\mathrm{m}+\mathrm{MSL}$, contour interval is $10 \mathrm{~m}$ ) of Silberleite catchment of Moxa, Germany. The shaded area is lower than the elevation of the gravimeter. The big round dot shows the location of the gravimeter, the weather station, a $\mathrm{V}$ notch and piezometer for groundwater. The small square dots show locations (upstream of V notch), where ground and surface water levels are monitored.

[8] Thuringia is located in a region in which maritime wet and continental dry influences practically balance. A main factor regarding the climate are the low mountain ranges. The mean annual temperature is $7.5^{\circ} \mathrm{C}$, where January is the coldest month (mean temperature of $-1.5^{\circ} \mathrm{C}$ ) and August the warmest (mean temperature of $16.5^{\circ} \mathrm{C}$ ). The average annual precipitation is approximately $700 \mathrm{~mm}$ with mean monthly precipitation ranging between 30 and $85 \mathrm{~mm}$.

[9] A Digital Elevation Model (DEM) of $20 \mathrm{~m}$ resolution covers an area of $4 \mathrm{~km}$ radius around the observatory. Other than the topography, we do not have detailed information regarding spatial heterogeneity (e.g., soils) of the catchment.

[10] The hourly gravity residuals, hereafter referred to as observed gravity residuals, are derived by filtering and reducing for Earth tides, polar motion, barometric pressure variations, and instrumental drift. More information about site specific gravity reduction is discussed by Kroner et al. [2004].

[11] The hydro-meteorological data in the vicinity of the observatory (big round dot in Figure 1) include hourly precipitation, groundwater (filter at $48 \mathrm{~m}$ below land surface), barometric pressure, temperature, wind speed, humidity, and illuminance. Moreover, we have occasionally sampled surface water levels at and discharge through a $\mathrm{V}$ notch installed in the Silberleite near the observatory. The above mentioned data collection started during the second half of 1999. At the end of 2003, additional piezometers were installed near the observatory and at a section (small square dots in Figure 1) upstream of the $\mathrm{V}$ notch at a depth ranging between 1 and $2 \mathrm{~m}$ to monitor the shallow (nearsurface) groundwater table (in the riparian area), together with an automatic water level recorder upstream of the $\mathrm{V}$ 


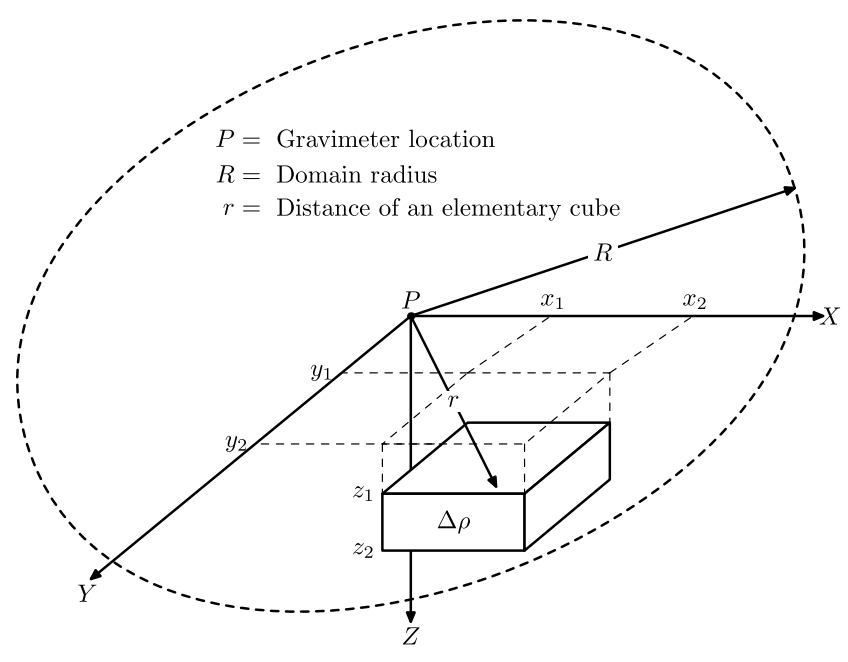

Figure 2. Sketch illustrating modeling of gravity variation from storage changes.

notch. Two additional rain gauges to check spatial variation in precipitation, and a solarimeter to convert illuminance data for estimation of net radiation, were also included in the new data collection program. On the basis of data availability for all variables, we kept the analysis and modeling limited for the period of 2004 and 2005.

\section{Modeling Approach}

[12] We hypothesized process-based links between hydrological change and gravity variation, and built our models accordingly. On the basis of the timescale of hydrological processes, we group water storage changes into (1) fast and (2) slow storage change, calculated for hourly and daily time steps respectively. The fast storage change process includes changes in root zone water content caused by precipitation, and changes in snow storage caused by snowfall and snowmelt. The slow storage change process includes water losses in root zone water storage through evapotranspiration and recharge, redistribution in saturated water storage, and discharge.

[13] In line with the above mentioned groups of hydrological processes, we classify the temporal gravity variation into the following.

[14] 1. Fast (e.g., hourly) gravity variation caused by precipitation.

[15] 2. Slow (e.g., daily) gravity variation caused by subsurface water redistribution.

[16] To model gravity variation, we need distributed information of mass (density) change. A distributed hydrological model is the logical tool to compute temporal gravity variation for different water storage changes. However, we do not have detailed information regarding spatial heterogeneity (e.g., soils) of the catchment except for its topography. In a previous study [Hasan et al., 2006], we found negligible subsurface (unsaturated) lateral flow and insignificant gravity variation due to canopy storage change. Thus a simple lumped water balance model for surface (snow) and near-surface (soil moisture) storage dynamics was chosen. Results from the lumped water balance model are then redistributed in the catchment using topographic information. Regarding saturated water storage dynamics, we divided the catchment into several hillslopes, based on topography. Thus a semidistributed hydraulic groundwater model for saturated storage and fluxes could be built.

\subsection{Gravity Model}

[17] Once the gravity residuals are derived, the remaining variation is primarily caused by mass changes of hydrological nature. On the basis of Newton's law of gravitation in a local Cartesian coordinate system, the vertical component of gravitation (gravity anomaly) at location $p(x, y, z)$ due to a disturbing mass at location $p^{\prime}\left(x^{\prime}, y^{\prime}, z^{\prime}\right)$ is computed by:

$$
\Delta g(p)=G \iint_{v} \int \frac{\Delta \rho\left(p^{\prime}\right)\left(z^{\prime}-z\right)}{\left|p^{\prime}-p\right|^{3}} d v
$$

where $\Delta \rho$ is the density difference of the disturbing mass relative to its surrounding, the volume element $d v=d x^{\prime} d y^{\prime} d z^{\prime}$ and the gravitation constant $G=6.673 \times 10^{-11} \mathrm{~m}^{3} \mathrm{~kg}^{-1} \mathrm{~s}^{-2}$.

[18] Closed-form solutions of equation (1) are available for simple bodies with constant density. For an elementary cube with the limits $x_{1}, x_{2}, y_{1}, y_{2}, z_{1}, z_{2}$ (Figure 2) we have [Nagy, 1966]:

$$
\begin{aligned}
\Delta g(r)= & G \Delta \rho[[[c-x \ln (y+r)-y \ln (x+r) \\
& \left.\left.\left.+z \arctan \frac{x y}{z r}\right]_{x_{1}}^{x_{2}}\right]_{y_{1}}^{y_{2}}\right]_{z_{1}}^{z_{2}}
\end{aligned}
$$

with $r=\sqrt{x^{2}+y^{2}+z^{2}}$. Equation (2) is the basis for all calculation of gravity variation. For any storage change, distributed computations of gravity variations are summed up, for the considered domain, to calculate the total gravity variation at the gravimeter location.

\subsection{Hydrological Model}

[19] Modeling of hydrological storage and fluxes was done in two steps. First, a lumped water balance model that provides average soil moisture and snow storage conditions. Second, the hillslope-storage Boussinesq (hsB) model [Troch et al., 2003] that provides semidistributed saturated water storage conditions in the catchment. Figure 3 illustrates the processes considered in our hydrological models. The storage dynamics modeled are then used to calculate changes in gravity.

\subsubsection{Lumped Water Balance Model}

[20] The lumped water balance model basically keeps track of hydrological stores and fluxes (shown in Figure 3) in the unsaturated zone and snowpack.

[21] The balance equation for the unsaturated zone is:

$$
L \frac{d \theta}{d t}=P-E-N-R
$$

where $L$ is depth of the unsaturated zone $(\mathrm{cm}), \theta$ is average soil moisture content $\left(\mathrm{m}^{3} \mathrm{~m}^{-3}\right), t$ is the time step (h), $P, E$, $N$, and $R$ are rates of precipitation (throughfall and snowmelt) $\left(\mathrm{cm} \mathrm{h}^{-1}\right)$, actual evapotranspiration $\left(\mathrm{cm} \mathrm{h}^{-1}\right)$, downward leakage (drainage) $\left(\mathrm{cm} \mathrm{h}^{-1}\right)$ to bedrock, and surface runoff (fraction of throughfall and snowmelt) $\left(\mathrm{cm} \mathrm{h}^{-1}\right)$ respectively. 


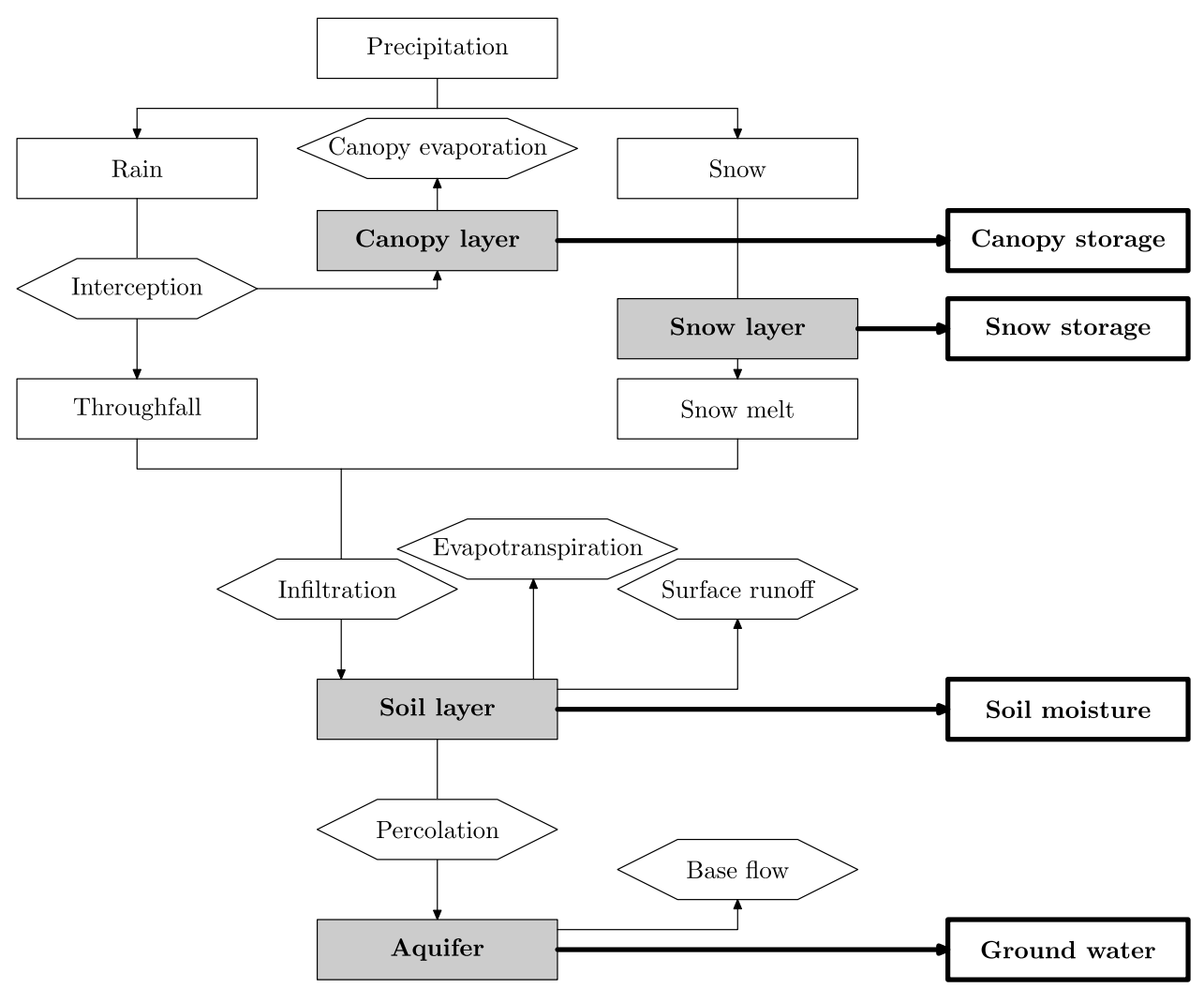

Figure 3. Schematic illustrating relevant hydrological processes considered in the models used.

[22] The balance equation for the snowpack is:

$$
\frac{d S_{s n}}{d t}=P_{s n}-M
$$

where $S_{s n}$ is depth of snow water equivalent $(\mathrm{cm}), t$ is the time step (h), $P_{s n}$ and $M$ are rates of snowfall $\left(\mathrm{cm} \mathrm{h}^{-1}\right)$ and snowmelt $\left(\mathrm{cm} \mathrm{h}^{-1}\right)$, both in water equivalent.

[23] Precipitation is classified as rain or snow based on a threshold temperature. Part of the rain is intercepted by the canopy layer, where interception is a function of available and maximum canopy storage capacity. Snowmelt is a simple degree-hour snowmelt algorithm that depends on a snowmelt factor:

$$
M=m T, \text { if, } T>0
$$

where $M$ is rate of snowmelt $\left(\mathrm{cm} \mathrm{h}^{-1}\right), m$ is snowmelt factor $\left(\mathrm{cm}{ }^{\circ} \mathrm{C}^{-1} \mathrm{~h}^{-1}\right.$ ) and $T$ is average air temperature $\left({ }^{\circ} \mathrm{C}\right.$ ). Throughfall and snowmelt are the main input to unsaturated zone, but not all of the throughfall and snowmelt reaches the unsaturated zone. We assume a fixed percentage of the catchment area, namely the riparian area, to be saturated and therefore will produce saturation excess overland flow. Part of the snowmelt never reaches the unsaturated zone by becoming direct runoff and evaporation (sublimation). During winter months, the upper soil layer of some part of the catchment is known to freeze, creating an impermeable layer. We assume a fixed percentage of the snowmelt to be lost and manually calibrate this parameter.

[24] Evapotranspiration is calculated using the relationship developed by Thornthwaite and Mather [1955] as a function of potential evapotranspiration, a vegetation coefficient (based on land use and vegetation), and average moisture content:

$$
E= \begin{cases}0, & \text { for : } \theta<\theta_{w} \\ c(t) E_{P}\left(\frac{\theta-\theta_{w}}{\theta_{f}-\theta_{w}}\right), & \text { for : } \theta<\theta_{f} \\ c(t) E_{P}, & \text { for : } \theta \geq \theta_{f}\end{cases}
$$

where $E_{P}$ is potential evapotranspiration $(\mathrm{cm}), c(t)$ is a vegetation coefficient that varies throughout the year, $\theta$ is average soil moisture content $\left(\mathrm{m}^{3} \mathrm{~m}^{-3}\right), \theta_{f}$ is moisture content at field capacity $\left(\mathrm{m}^{3} \mathrm{~m}^{-3}\right)$ and $\theta_{w}$ is moisture content at wilting point $\left(\mathrm{m}^{3} \mathrm{~m}^{-3}\right)$. The actual evapotranspiration varies linearly between $E_{P}$, when soil moisture content is at or above field capacity, and becomes zero when soil moisture is below the wilting point. Monthly values of vegetation coefficients are based on Jensen [1973].

[25] Drainage is calculated using Darcy's law with the unit-gradient assumption. Using the Campbell [1974] parameterization yields:

$$
N=K_{s}\left(\frac{\theta}{\phi}\right)^{2 b+3}
$$

where $K_{s}$ is the saturated hydraulic conductivity, $\phi$ is soil porosity and $b$ is a pore size distribution parameter. Since $\phi$ and $b$ are generally correlated with $K_{s}$, we related these to $K_{s}$ by linear regression with $\ln \left(K_{s}\right)$, fitted to the data provided 
Table 1. Parameters of the Water Balance Model

\begin{tabular}{ll}
\hline Time step & $1 \mathrm{~h}$ \\
Temperature threshold rain/snow & $1.5^{\circ} \mathrm{C}$ \\
Snowmelt factor (forest) & $2.3 \mathrm{~mm}^{\circ} \mathrm{C}^{-1} \mathrm{~d}^{-1}$ \\
Maximum canopy storage & $2 \mathrm{~mm}$ \\
Canopy evaporation during rain & $0.04 \mathrm{~mm} \mathrm{~h}^{-1}$ \\
Canopy evaporation factor & \\
$\quad$ during no rain (fraction of $E_{P}$ ) & 0.5 \\
Residual moisture content & 0.02 \\
Moisture content at field capacity & 0.27 \\
Moisture content at wilting point & 0.11 \\
Saturated hydraulic conductivity & $1 \mathrm{~mm} \mathrm{~d}$ \\
Soil porosity & 0.45 \\
Fraction of riparian area & 0.02 \\
Soil depth (variable) & $50 \mathrm{~cm}$ \\
Initial soil moisture storage & $8 \mathrm{~cm}$ \\
\hline
\end{tabular}

by Clapp and Hornberger [1978]. This yields [Teuling and Troch, 2005]:

$$
\begin{aligned}
& \phi=-0.0147 \ln \left(K_{s}\right)+0.545 \\
& b=-1.24 \ln \left(K_{s}\right)+15.3
\end{aligned}
$$

[26] Moisture above field capacity can drain to the underlying aquifer. Thus obtained drainage (recharge) is the input to the semidistributed hsB model.

[27] Runoff or direct runoff is mainly a fraction of throughfall, above a certain threshold, generated as saturation excess runoff in the riparian area. The riparian area is determined as a fraction of the whole catchment as derived from topographic analysis.

[28] The parameters of the water balance model are listed in Table 1. Parameters related to partitioning of precipitation in rain and snow and canopy storage and evaporation parameters are based on Boll et al. [1998]. Interception is calculated for spruce trees based on Lankreijer et al. [1999]. The soil properties are based on field and laboratory measurements on soil samples.

\subsubsection{Hillslope-Storage Boussinesq (hsB) Model}

[29] The hsB model [Troch et al., 2003] is a one-dimensional hydraulic groundwater model that describes the dynamics of saturated storage $S$ along a hillslope. The hsB model is derived by combining the Boussinesq equation for sloping aquifers (using the Dupuit-Forchheimer assumptions) and the definition of storage capacity as

$$
S_{c}(x)=D(x) w(x) f
$$

where $D(x)$ is average aquifer depth along the hillslope, $w(x)$ is hillslope width, and $f$ is drainable porosity (or specific yield).

[30] The resulting nonlinear hsB equation then reads

$$
\frac{\partial S}{\partial t}=\frac{k \cos \alpha}{f^{2}} \frac{\partial}{\partial x}\left[\frac{S}{w}\left(\frac{\partial S}{\partial x}-\frac{S}{w} \frac{\partial w}{\partial x}\right)\right]+\frac{k \sin \alpha}{f} \frac{\partial S}{\partial x}+N w
$$

where $k$ is saturated lateral (to distinguish it from $K_{s}$ used above) hydraulic conductivity, $\alpha$ is slope angle, and $N$ is recharge rate (see Troch et al. [2003] for more details).

[31] The topographic parameters of hsB, hillslope length $l$, hillslope width function $w(x)$ and average hillslope gradient $\alpha$ are computed from a raster DEM. The $20 \mathrm{~m}$ resolution DEM of the Moxa catchment was broken up into individual hillslope elements (Figure 4). The field based perception of the channel network extent and a topographic analysis based channel network map was compared to decide the hillslope delineation.

\subsection{Model Input and Conditions}

[32] The water balance model inputs consist of precipitation and temperature, which are collected at the observatory. Other forcings include potential evapotranspiration (estimated from weather data) and a vegetation coefficient. We calculated potential evapotranspiration by the ASCE Penman-Monteith (full) method using the REF-ET software developed at Kimberly, Idaho [Allen, 2000]. Required site parameters are the elevation of the weather station above the ground surface, the elevation of the site above mean sea level, and the latitude of the site. Required data for hourly time steps are mean hourly air temperature, relative humidity, wind speed, and solar radiation. We estimated solar radiation converted from illuminance data.

[33] Illuminance is the total amount of visible light illuminating a point on a surface from all directions above the surface. Therefore illuminance is equivalent to irradiance weighted with the response curve of the human eye. The ratio between illumination and radiation intensity can vary with solar zenith distance [List, 1968; Kimball, 1924]. However, comparing solar radiation data from recently installed solarimeter next to the existing illuminance meter, we found good (cross-correlation coefficient of 0.92) agreement between illuminance and solar radiation.

[34] Actual evapotranspiration is based on moisture content, potential evapotranspiration, and a vegetation coefficient. The latter has a seasonal variation. It is assumed that the ET coefficient is $100 \%$ for the months November to March, $110 \%$ for the months April, May, September, and October, and $115 \%$ for the months June to August [Jensen, 1973].

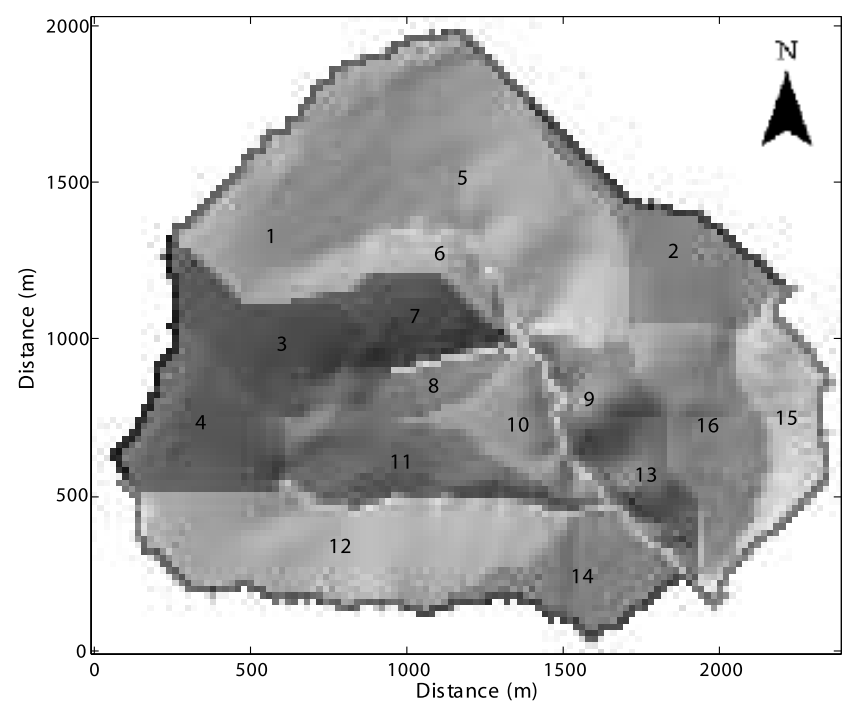

Figure 4. From catchment to hillslopes: hillslope delineation of Moxa catchment. The numbers and shades (colors) show different hillslopes. 


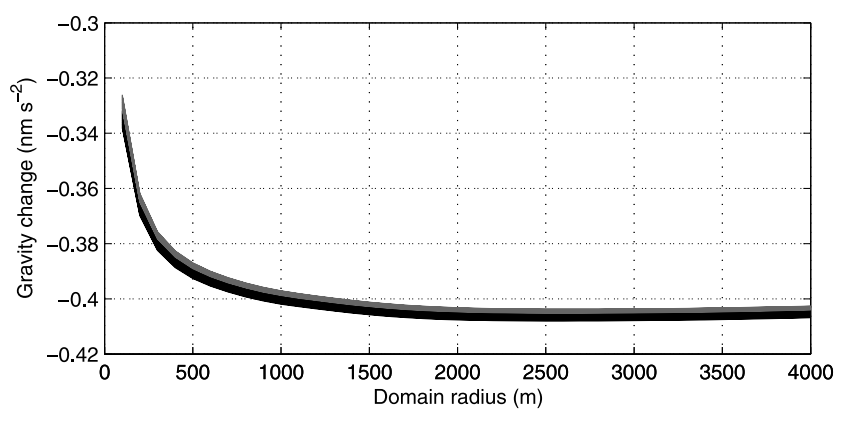

Figure 5. Range of change in gravity caused by $1 \mathrm{~mm}$ rise in soil moisture (black) or snow (gray) in 0.1 to $2 \mathrm{~m}$ soil or snow depth for different domain radius.

[35] The discharge data, used for model calibration and validation, are from occasionally sampled surface water levels at, and discharge through a $\mathrm{V}$ notch installed in the Silberleite. Because of hydraulically improper design and construction, the $\mathrm{V}$ notch is neither a broad nor a sharp crested weir. However, we constructed a replica of the existing weir in the laboratory. On the basis of available data and current instrumentation information, we estimated the relationship between upstream water level and discharge through the $\mathrm{V}$ notch.

[36] Simulation of the lumped water balance model was done at hourly time steps, while hsB model simulation was performed at daily time steps. Considering the size of the catchment and comparing the precipitation data collected from different rain gauges, spatially uniform input forcing was applied. For the same reason (small catchment) and for the reason of simulation time steps (daily, larger than the time of concentration of the catchment), we did not consider discharge routing. For hsB model simulations, the initial water table conditions for different hillslopes were assumed to be the steady state water tables from estimated average recharge over a long period. We assumed fixed boundary conditions for the hsB model: no flow at the divide and zero water table head at the outlet.

\section{Sensitivity Analysis of Local Gravity Variation}

[37] Here we present the results of a sensitivity analysis testing the effects of storage change on gravity. The analysis is based on local topography and some simplifying assumptions of where and how much water storage changes in soils and aquifers. This analysis is done for both fast (near surface) and slow (aquifer) water storage changes as defined in section 3. This analysis provides a better understanding of expected gravity residuals dynamics in our catchment.

[38] For fast storage change, we consider a range of snow depth and soil layer thickness from 0.1 to $2 \mathrm{~m}$ at an interval of $0.1 \mathrm{~m}$. In each case, a uniform distribution of unit (1 mm equivalent water) storage increase is assumed. This increase in storage is then converted to a change in density, the variation of which is caused by the assumed snow depth or soil layer thickness. Finally the change in gravity is calculated as described in section 3.1. We also consider different horizontal domains around the gravimeter, by varying the radius from 100 to $4000 \mathrm{~m}$ at an interval of $100 \mathrm{~m}$.

[39] For slow storage change, we consider an aquifer parallel to the local topography, where the horizontal domain is limited to the catchment (Figure 1). We vary the depth of the bedrock beneath the surface and calculate the change in gravity for a unit $(1 \mathrm{~mm})$ storage change in the aquifer. We further look at a condition where the aquifer is slowly filling up. We assume a situation, where a $10 \mathrm{~m}$ deep empty aquifer is gradually filled up and calculate related gravity change.

[40] We find $\sim 0.40 \mathrm{~nm} \mathrm{~s}^{-2}$ instantaneous change in gravity caused by $1 \mathrm{~mm}$ change in soil moisture or equivalent snow storage. Most of the gravity variation due to fast storage change can be modeled if we consider a radius of about $1 \mathrm{~km}$ around the gravimeter. We also find that the variation in snow depth or soil layer thickness has an insignificant effect on changing gravity (overlapping lines in Figure 5). This analysis confirms our previous findings [Hasan et al., 2006], where we used time series modeling to compute an impulse response function based on precipitation and gravity observation data. According to that blackbox model, we found $\sim 0.35 \mathrm{~nm} \mathrm{~s}^{-2}$ instantaneous change in gravity caused by $1 \mathrm{~mm}$ precipitation. The higher value in the current analysis can be explained by the fact that for a storage increase of $1 \mathrm{~mm}$, a precipitation amount in excess of $1 \mathrm{~mm}$ is needed.

[41] We find that the change in gravity varies both in sign and magnitude for the same amount of water storage change (Figure 6). Unlike near surface water storage, for saturated water storage (groundwater), the vertical extent of the domain changes because of temporal variation of the groundwater table. Thus there are time varying relationships between the change in groundwater storage and gravity, because of topography and location of mass change. Figure 6 clearly shows a water table depth dependent temporal switch in the relationship between groundwater storage and gravity. Figure $6 \mathrm{~b}$ shows different water table depths, where such a switching relationship can occur. We can justify the horizontal extent of saturated water storage component to be considered in gravity modeling, as we see gravity becomes less sensitive with increasing radius (overlapping lines in Figure 6a). We can also set a limit to the vertical extent of the hydrological domain, as below a depth of $30 \mathrm{~m}$, gravity change becomes less sensitive to the depth of the aquifer (Figure 6a).

\section{Gravity Variation and Hydrology}

[42] The sensitivity analysis (section 4) is, however, limited to the assumption of a saturated water table and its temporal variation parallel to the topography. In a simple situation, where all considerable water storage changes are either above or below a gravimeter, gravity variation data can be useful in assimilation of storage changes. In reality, where considerable water storage changes occur both above and below a gravimeter, the question is if and how we can use the observed gravity field in hydrological modeling.

[43] The following steps are considered here in applying and investigating gravity residuals in hydrological modeling.

[44] 1. From the available DEM, the gravity model is built as a distributed version of equation (2) for density variations caused by different storage changes.

[45] 2. The parameters of the lumped water balance model are calibrated based on Nash-Sutcliffe model 

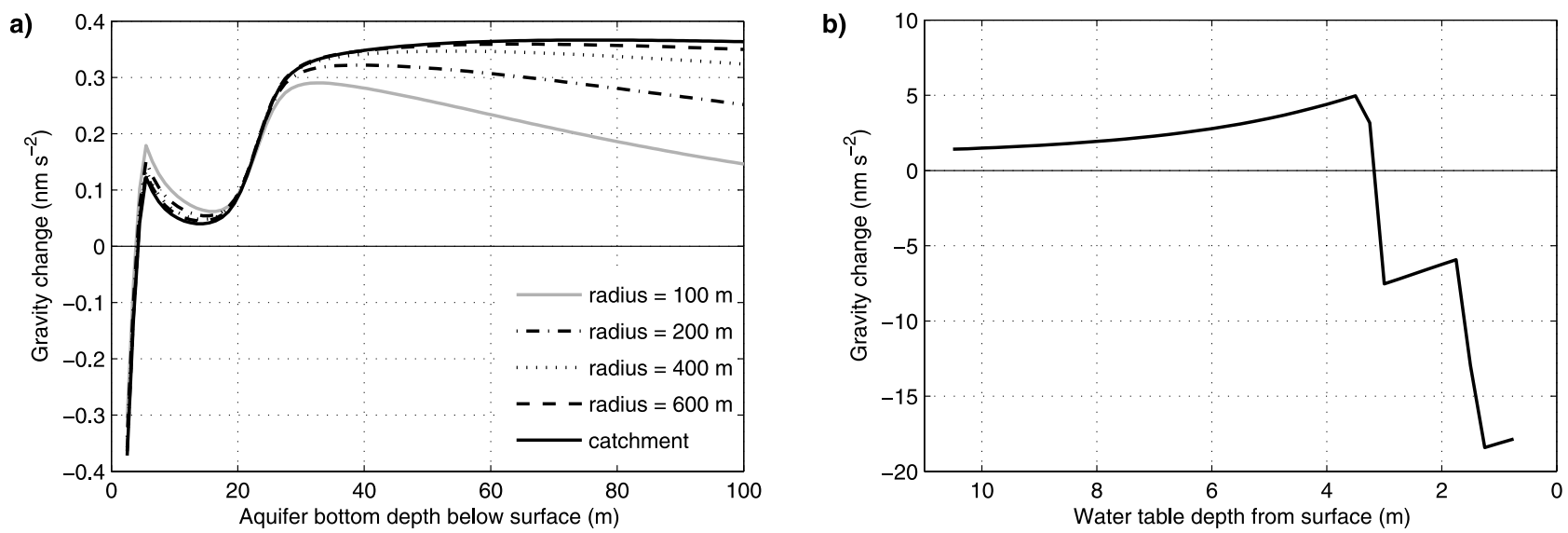

Figure 6. Analysis of slow storage change. (a) Change in gravity caused by $1 \mathrm{~mm}$ rise in water table in a 2-m deep aquifer, when we move the aquifer vertically downward parallel to the topography. Lines show the effect on gravity for different domain radius and the catchment considered. (b) Change in gravity caused by filling up of a 10-m deep aquifer, with the water table parallel to the surface topography.

efficiencies [Nash and Sutcliffe, 1970] for fast (hourly) gravity variation.

[46] 3. The output from the lumped water balance model is then used as a forcing (recharge) for the semidistributed hsB model.

[47] 4. The simulated saturated storage changes from hsB are used to calculate slow (daily) gravity variations.

[48] 5. Different simulations for different recharge conditions in hsB are tested, using Nash-Sutcliffe model efficiencies, to see how gravity field data can be useful in hydrological modeling.

[49] 6. The local hydrological effect on gravity is quantified and gravity variations with and without hydrological reductions are compared.

[50] 7. The final output of the hydrological models applied to the catchment is the discharge through the $\mathrm{V}$ notch near the gravimeter.

\subsection{Fast Storage Change}

[51] The lumped water balance model gave us an estimate of hourly variation in average soil moisture and snow storage for the area around the gravimeter. These storage changes are redistributed spatially with the aid of topographic information and equation (2) is applied to compute gravity variations. Fast gravity variation, modeled from soil moisture and snow storage change, is compared with observed gravity variation in Figure 7 . Effective soil depth (soil depth $\times$ porosity) for the lumped model was calibrated using hourly gravity data and Nash-Sutcliffe model efficiencies as the measure for goodness of fit (Table 2). The model results agree well with the observed gravity signal both in magnitude and dynamics. For a given soil depth, porosity does not play a significant role in changing the fluxes, as the average soil column never reaches saturation. However, as we used field capacity in affecting actual evapotranspiration and drainage, we looked at the effect of varying field capacity (Table 2 ).

[52] Table 2 compares the efficiency of the lumped water balance model in reproducing the gravity residuals. We find general good agreement between observed and modeled gravity residuals. The poor model efficiency during some periods indicates other effective dynamics (e.g., lateral redistribution of saturated water) not considered in modeling the fast storage change. In the modeled gravity, negative

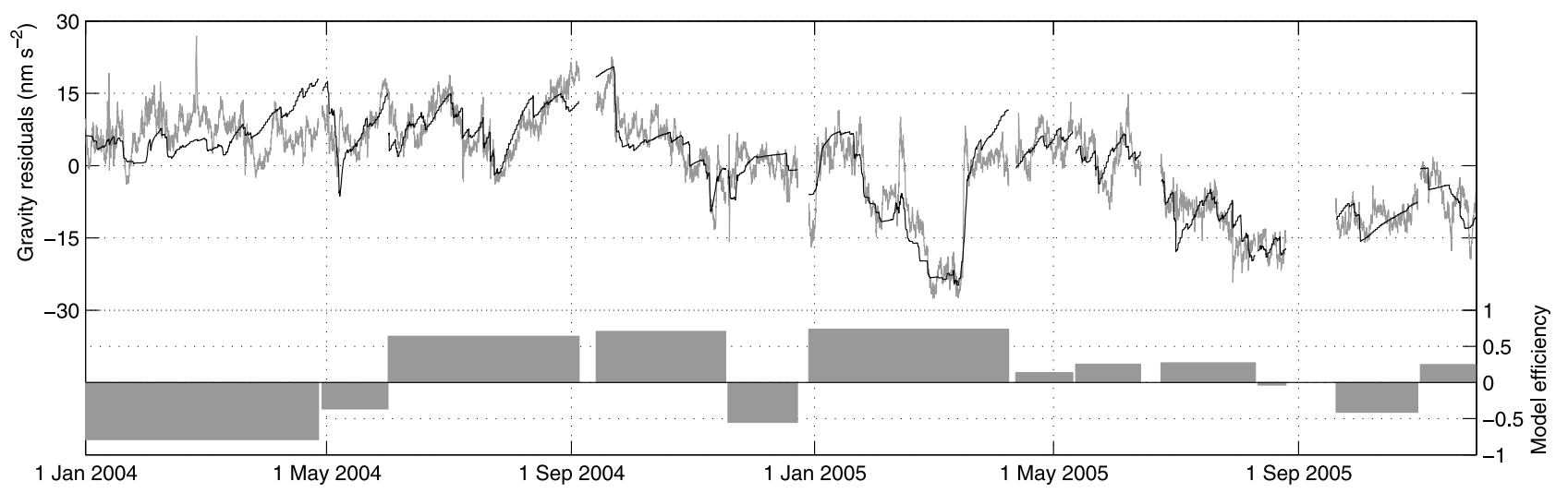

Figure 7. Observed (gray) and modeled (black) fast gravity variation. The modeled residuals contain effects of changes in soil moisture and snow storage. The gray bars at the bottom show the model efficiency (Nash-Sutcliffe coefficients) for different periods separated by missing data. 
Table 2. Parameters for Lumped Water Balance Model (NashSutcliffe Model Efficiencies are Calculated for Gravity Residuals)

\begin{tabular}{llllllll}
\hline Soil depth, cm & 20.0 & 30.0 & 40.0 & 50.0 & 60.0 & 70.0 & 80.0 \\
Efficiency & 0.57 & 0.65 & 0.68 & 0.70 & 0.67 & 0.60 & 0.56 \\
Field capacity, \% & & 20.0 & 25.0 & 27.0 & 30.0 & 40.0 & \\
Efficiency & & 0.64 & 0.66 & 0.70 & 0.65 & 0.60 & \\
\hline
\end{tabular}

spikes can be explained by quick addition to water storage (e.g., rain, snow), while positive spikes can be explained by snowmelt.

\subsection{Slow Storage Change}

[53] The hsB model, coupled with the water balance model, provides estimates of daily variation in saturated water storage for different hillslopes in the catchment. Ranges of slow gravity variations were calculated from saturated water storage change for all the hillslopes of the catchment with changing bedrock positions (2 to $100 \mathrm{~m}$ below surface). Analyzing the gravity variation caused by saturated storage changes from individual hillslopes, we find that hillslope 9 and 10 (see Figure 4 for their location within the catchment) contribute most strongly to gravity changes. Figure 8 shows the effect of all hillslopes in changing gravity by saturated storage dynamics. The switch in relationship between gravity and saturated storage is clearly visible. The change in this relationship occurs at a different depth for different hillslopes, which can be explained by the different positions of the hillslopes, relative to the gravimeter. Considering the complexity in the groundwater-gravity relation, we decide to employ gravity variations to calibrate the depth to the bedrock of hillslopes 9 and 10. However, we do not neglect the effect of saturated water dynamics on gravity and look at the likely range of gravity variations modeled from saturated water dynamics. In Figure 9, the modeled slow gravity variation range is compared with the residuals obtained from observed and modeled gravity variation.

[54] The parameters of the hsB model (effective drainable porosity and hydraulic conductivity) were calibrated based on Nash-Sutcliffe model efficiencies for observed and modeled discharge (Table 3) through the V notch. Figure 9 clearly demonstrates that peaks in saturated water storage can be associated to some positive peaks in temporal gravity variation. However, we also encounter periods of low storage conditions or no storage changes, with observed gravity variations. Hence this model does not ensure capturing gravity variation during low storage conditions. During these conditions, local storage change may occur in the form of redistribution, which may not change the global storage quantity. The obvious explanation for not capturing gravity variations during low storage conditions is the lack of detailed information (e.g., location) regarding groundwater redistribution. Another possible explanation is that the observed gravity variations during low storage conditions are not caused by local hydrological changes.

\subsection{Hydrological Gravity Reductions}

[55] Using the results presented in Figure 9, we optimized the effect of saturated water storage change on gravity variation for hillslope 9 and 10 . The effective bedrock positions of hillslope 9 and 10 are $\sim 22.5$ and $12.5 \mathrm{~m}$ below the surface, respectively. The local hydrological effects on gravity are calculated using the results obtained from sensitivity analysis and hydrological model simulations. Observed gravity residuals are reduced for the local hydrological effect, and the resulting gravity residuals are presented in Figure 9. The hydrological models explain 80\% of the variance of observed gravity residuals, which is $65.42 \mathrm{~nm}^{2} \mathrm{~s}^{-4}$, while the variance of gravity residuals reduced for local hydrological effect is $12.85 \mathrm{~nm}^{2} \mathrm{~s}^{-4}$.

\subsection{Final Model Output}

[56] We examine the final model output by comparing modeled with observed discharge at the $\mathrm{V}$ notch. For various recharge conditions (i.e., lumped model output), we performed different simulations of the hsB model and checked the model performance, quantified as Nash-Sutcliffe model efficiencies with respect to discharge (Table 2). We also examine the hsB model parameters and find hydraulic conductivity to be less effective than drainable porosity (shown in Table 3).

[57] Figure 10 shows a comparison of observed and modeled discharge through the V notch near the gravimeter. The model results agree well with the observed signal both in magnitude and dynamics during some periods, while during other periods the model overestimates the discharge. While comparing the hydrographs, please note that during some winters, the data collection system was hampered by frozen surface conditions. As a result, some snowmelt events are missing in the observed discharge data.

\section{Discussion}

[58] We employed terrestrial gravity observations from a single location to constrain hydrological models in a small catchment at the Geodynamics Observatory Moxa, Germany. A simple lumped water balance model, constrained by fast gravity variations, gives us robust and effective input conditions for the semidistributed hillslope-storage Boussinesq model. The hsB model successfully reproduces the discharge magnitude and dynamics. Despite the fact that the parameters used in the lumped water balance model are average over the entire catchment, our models give encouraging results for both hydrology and gravity. Considering

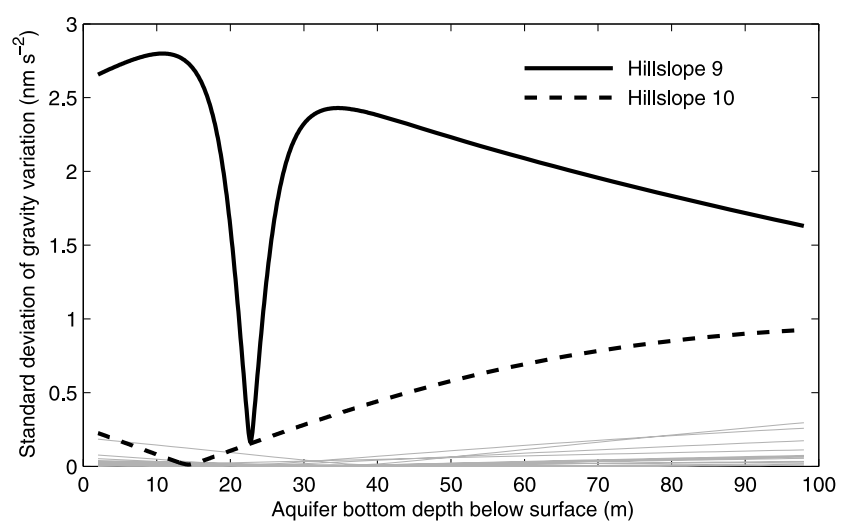

Figure 8. Effect of different hillslopes in the catchment on gravity variation due to saturated water storage change. Hillslope numbers are shown in Figure 4. Legend shows only the most effective hillslopes, while the other hillslopes' effects are plotted in thin gray line. 


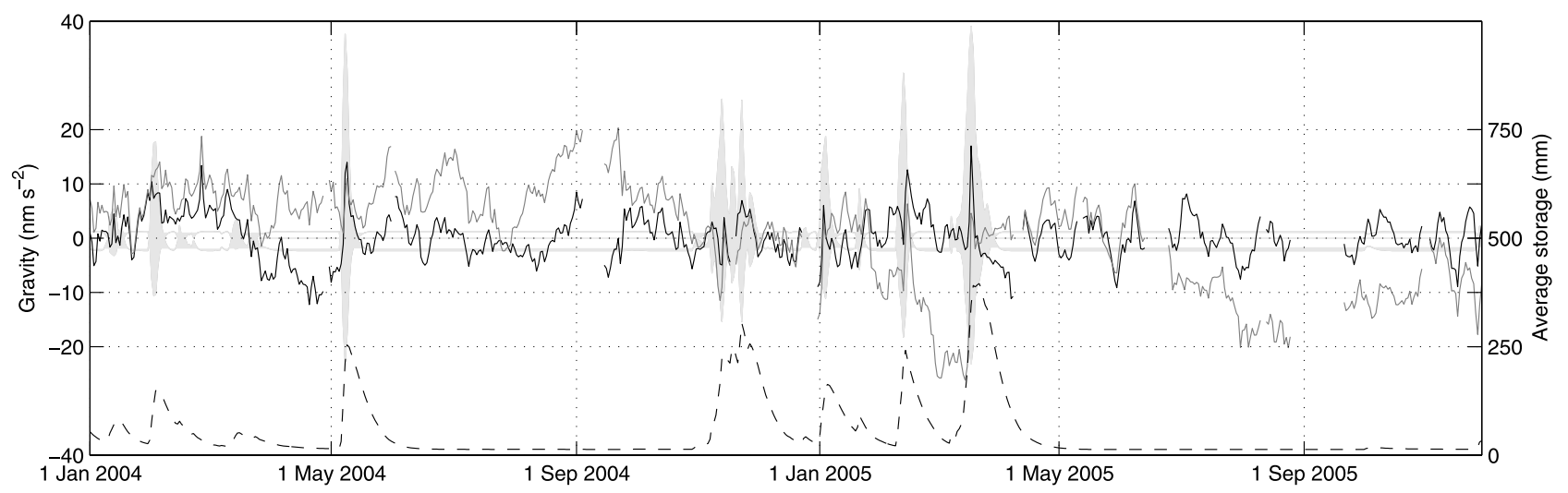

Figure 9. Range of gravity variation for a varying bedrock depth, ranging from 2 to $100 \mathrm{~m}$ below surface (shaded gray area), gravity residuals before (solid gray line) and after (solid black line) local hydrological reductions, along with modeled catchment average saturated water storage condition (dashed black line).

the observed gravity change as an additional integrator of catchment-scale hydrological response, and therefore using it to constrain hydrologic models for that catchment proves to bring a new way of validating water balance estimates.

[59] Geographical position relative to the gravimeter plays an important role in the relationship between storage and gravity variation. The topography based analysis, using available DEM and possible storage variations distributed in the catchment, shows the extent of the hydrological domain affecting point-scale gravity. Despite the encouraging results we obtained in hydrological modeling, this paper also shows the limitations in modeling of temporal gravity variation caused by hydrological redistribution in the local geophysical conditions, where storage changes occur both above and below a gravimeter. However, by providing the likely range of variation in gravity caused by local hydrological changes, we made it possible to have a gravity time series, free from local hydrological effects.

[60] Hinderer et al. [2006] investigated seasonal changes of the Earth's gravity field from GRACE (Gravity Recovery and Climate Experiment [Tapley et al., 2004]), and made a comparison with surface gravity measurements in Europe from the GGP network and hydrological models for continental soil moisture and snow. Following their findings and discussions, terrestrial gravity variations observed at the point-scale have to be free from local effects, in order to apply in larger-scale hydrological investigations. In this study, we provided calculation of gravity variation caused by local hydrological changes that explain $80 \%$ of observed gravity variation.

[61] Considering the complex geophysical conditions and limited knowledge of subsurface variability in detecting local hydrological effects, satellite geodesy has the potential of simplifying the geophysical conditions to some extent. Once local gravity variations are free from local effect, GRACE and GRACE-like projects can be used in combination with superconducting gravimeter data for basin-scale hydrological modeling and validation.

\section{Conclusion}

[62] This paper reports the findings of a study applying terrestrial gravity observations to aid catchment-scale hy- drological modeling. Our study uses simple water balance models to simulate catchment water storage dynamics and the related variation of gravity at a point in the catchment. We classified the water storage changes into fast and slow changes to analyze the hydrological effect on gravity and to evaluate hydrological models by means of gravity variation. The fast storage changes are changes in root zone and snow water content, calculated at hourly time steps. The slow storage changes are changes in saturated water, calculated at daily time steps.

[63] By means of a sensitivity analysis, we show what parts of the gravity variation can be estimated from hydrological models. We find that a $1 \mathrm{~mm}$ change in soil moisture or snow water equivalent causes $\sim 0.40 \mathrm{~nm} \mathrm{~s}^{-2}$ instantaneous change in gravity. We also show that the horizontal extent of the hydrological domain in affecting gravity at the measurement location has a radius of $\sim 1 \mathrm{~km}$ around the gravimeter. Furthermore, we show how saturated water storage change has a strong nonlinear and state-dependent relationship with gravity.

[64] In order to apply gravity data in hydrological modeling, we built models according to the classification of water storage changes (fast and slow). The fast storage change is modeled by a lumped water balance model, the parameters of which are constrained by gravity variation data. The output of the lumped water balance model is then used as the input forcing of a semidistributed hydraulic groundwater model for the slow storage change. The coupled modeling system successfully reproduces both gravity and discharge dynamics. Our hydrological models explain $80 \%$ of the variance of observed gravity residuals.

[65] The results from this paper show the potential of using observed gravity change as an integrator of catch-

Table 3. Parameters for Semidistributed hsB Model (NashSutcliffe Model Efficiencies are Calculated for Discharge)

\begin{tabular}{llllll}
\hline Drainable porosity, \% & 0.05 & 0.10 & 0.15 & 0.20 & 0.25 \\
Efficiency & 0.55 & $\mathbf{0 . 6 0}$ & 0.59 & 0.57 & 0.56 \\
Hydraulic conductivity, $\mathrm{m} \mathrm{h}^{-1}$ & 0.80 & 0.90 & 1.00 & 1.10 & 1.20 \\
Efficiency & 0.59 & 0.60 & 0.60 & 0.60 & 0.59 \\
\hline
\end{tabular}




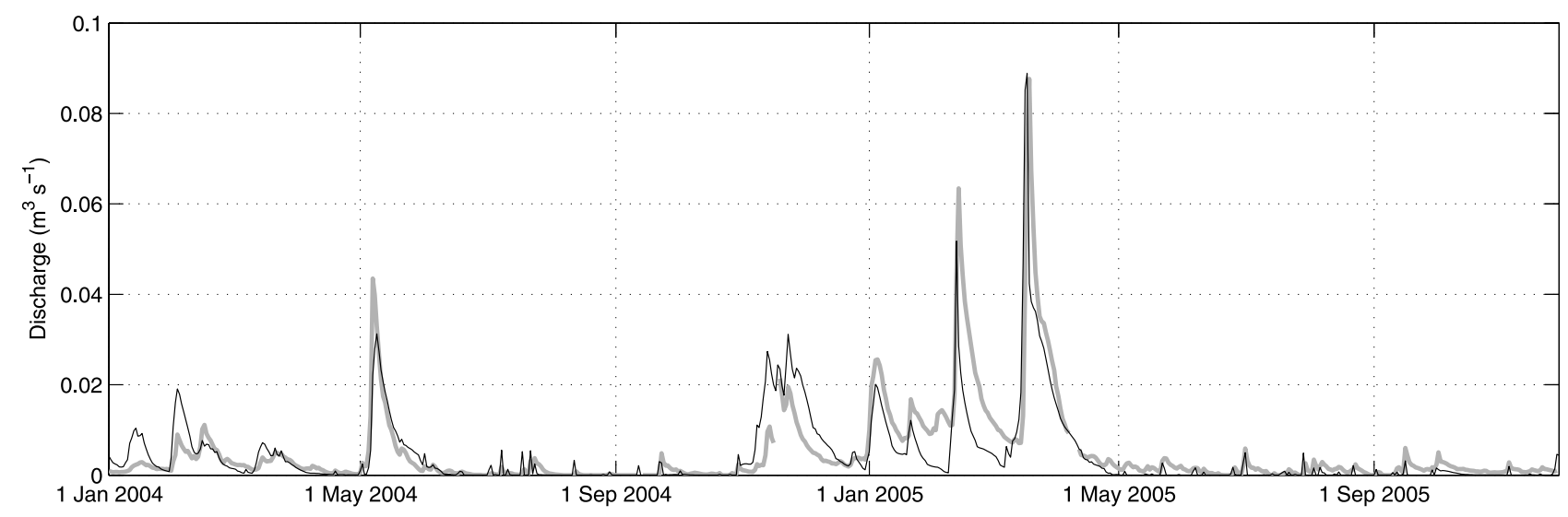

Figure 10. Observed (gray) and modeled (black) discharge through the existing V notch near the gravimeter. Note that there are missing data in observed time series.

ment-scale hydrological response (similar in nature as discharge measurements).

[66] Acknowledgments. This work is supported by WIMEK (Wageningen Institute for Environment and Climate Research) and partly supported by the AGU (American Geophysical Union) Horton Research Grant. We thank Wernfrid Kühnel and Matthias Meininger (Geodynamic Observatory Moxa, Germany), Hennie Gertsen, Anton Dommerholt and Roel Dijksma (Wageningen University, Netherlands) for their assistance in the laboratory and field work. We are grateful to Donald Pool (USGS, Tucson, USA) for useful discussion of the work and Remko Uijlenhoet (Wageningen University, Netherlands) for his careful and detailed review of the previous version of this manuscript. Comments and suggestions from D. Harry and two anonymous reviewers are also gratefully acknowledged.

\section{References}

Allen, R. G. (2000), REF-ET Reference Evapotranspiration Calculator, University of Idaho, Kimberly, Idaho.

Alsdorf, D. E., and D. P. Lettenmaier (2003), Tracking fresh water from space, Science, 301(5639), 1491-1494.

Bales, R. C., N. P. Molotch, T.H. Painter, M. D. Dettinger, R. Rice, and J. Dozier (2006), Mountain hydrology of the western United States, Water Resour. Res., 42, W08432, doi:10.1029/2005WR004387.

Bastiaanssen, W. G. M., H. Pelgrum, P. Droogers, H. A. R. de Bruin, and M. Menenti (1997), Area-average estimates of evaporation, wetness indicators and top soil moisture during two golden days in EFEDA, Agric. For. Meteorol., 87(2-3), 119-137.

Boll, J., E. S. Brooks, C. R. Campbell, C. O. Stockle, S. K. Young, J. E. Hammel, and P. A. McDaniel (1998), Progress toward development of a GIS based water quality management tool for small rural watersheds: Modification and application of a distributed model, paper presented at Annual International Meeting, ASAE, Orlando, Florida.

Bower, D. R., and N. Courtier (1998), Precipitation effects on gravity measurements at the Canadian absolute gravity site, Phys. Earth Planet. Inter., 106(3-4), 353-369.

Campbell, G. S. (1974), A simple method for determining unsaturated conductivity from moisture retention data, Soil Sci., 117(6), 311-314.

Chao, B. F. (1994), The Geoid and Earth Rotation, in Geoid and Its Geophysical Interpretations, edited by P. Vanicek and N. T. Christou, pp. 285-298, CRC Press, Boca Raton, Fla.

Clapp, R., and G. Hornberger (1978), Empirical equations for some soil hydraulic properties, Water Resour. Res., 14(4), 601-604.

Crossley, D. J., and S. Xu (1998), Analysis of superconducting gravimeter data from Table Mountain, Colorado, Geophys. J. Int., 135(3), 835-844.

Crossley, D., et al. (1999), Network of superconducting gravimeters benefits several disciplines, Eos Trans. AGU, 80(11), 121-126.

Goodkind, J. M. (1999), The superconducting gravimeter, Rev. Sci. Instrum., 70(11), 4131-4152.

Harnisch, M., and G. Harnisch (2002), Seasonal variations of hydrological influences on gravity measurements at Wettzell, Bull. Inf. Marées Terr., $137,10,849-10,861$
Hasan, S., P. A. Troch, J. Boll, and C. Kroner (2006), Modeling the hydrological effect on local gravity at Moxa, Germany, J. Hydrometeorol., 7(3), 346-354, doi:10.1175/JHM488.1.

Hinderer, J., O. B. Andersen, F. Lemoine, D. Crossley, and J. P. Boy (2006), Seasonal changes in the European gravity field from GRACE: A comparison with superconducting gravimeters and hydrology model predictions, J. Geodyn., 41(1-3), 59-68, doi:10.1016/j.jog.2005.08.037.

Jackson, T. J., D. M. Le Vine, A. Y. Hsu, A. Oldak, P. J. Starks, C. T. Swift, J. D. Isham, and M. Haken (1999), Soil moisture mapping at regional scales using microwave radiometry: The Southern Great Plains Hydrology Experiment, IEEE Trans. Geosci. Remote Sens., 37(5), 2136-2151.

Jensen, M. E. (1973), Consumptive Use of Water and Irrigation Water Requirements, 215 pp., ASCE, New York.

Kimball, H. H. (1924), Records of total solar radiation intensity and their relation to daylight intensity, Mon. Weather Rev, 52(10), 473-479.

Krajewski, W. F., et al. (2006), A remote sensing observatory for hydrologic sciences: A genesis for scaling to continental hydrology, Water Resour. Res., 42, W07301, doi:10.1029/2005WR004435.

Kroner, C. (2001), Hydrological effects on gravity at the Geodynamic Observatory Moxa, J. Geod. Soc. Jpn., 47(1), 353-358.

Kroner, C., T. Jahr, and G. Jentzsch (2004), Results from 44 months of observations with a superconducting gravimeter at Moxa/Germany, J. Geodyn., 38(3-5), 263-280.

Lankreijer, H., A. Lundberg, A. Grelle, A. Lindroth, and J. Seibert (1999), Evaporation and storage of intercepted rain analysed by comparing two models applied to a boreal forest, Agric. For. Meteorol., 98-99, 595604.

List, R. J. (1968), Smithsonian Meteorological Tables, vol. 114, 6th ed., 527 pp., Smithsonian Institution Press, Washington, D. C.

Mäkinen, J., and S. Tattari (1988), Soil moisture and groundwater: Two sources of gravity variations, Bull. Inform. Marées Terr., 62, 103-110.

Nagy, D. (1966), The gravitational attraction of a right rectangular prism, Geophysics, 31, 362-371.

Nash, J. E., and J. V. Sutcliffe (1970), River flow forecasting through conceptual models. part I: A discussion of principles, J. Hydrol., 10(3), 282290.

Njoku, E. G., and L. Li (1999), Retrieval of land surface parameters using passive microwave measurements at $6-18 \mathrm{GHz}$, IEEE Trans. Geosci. Remote Sens., 37(1), 79-93.

Peter, G., P. G. Klopping, and K. A. Berstis (1995), Observing and modeling gravity changes caused by soil moisture and groundwater table variations with superconducting gravimeters in Richmond, Florida, USA, Cahiers Centre Eur. Géodyn. Séismol., 11, 147-159.

Pool, D. R. (2005), Variations in climate and ephemeral channel recharge in southeastern Arizona, United States, Water Resour. Res., 41, W11403, doi:10.1029/2004WR003255.

Pool, D. R., and J. H. Eychaner (1995), Measurements of aquifer-storage change and specific yield using gravity Surveys, Ground Water, 33(3), 425-432, doi:10.1111/j.1745-6584.1995.tb00299.x.

Rodell, M., and J. S. Famiglietti (1999), Detectability of variations in continental water storage from satellite observations of the time dependent gravity field, Water Resour. Res., 35(9), 2705-2724. 
Rodell, M., and J. S. Famiglietti (2001), An analysis of terrestrial water storage variations in Illinois with implications for the Gravity Recovery And Climate Experiment (GRACE), Water Resour. Res., 37(5), 13271340.

Rodell, M., and J. S. Famiglietti (2002), The potential for satellite-based monitoring of groundwater storage changes using GRACE: The High Plains aquifer, Central US, J. Hydrol., 263(1-4), 245-256, doi:10.1016/ S0022-1694(02)00060-4.

Su, Z. (2002), The Surface Energy Balance System (SEBS) for estimation of turbulent heat fluxes, Hydrol. Earth Syst. Sci., 6(1), 85-99.

Su, Z., P. A. Troch, and F. P. de Troch (1997), Remote sensing of bare surface soil moisture using EMAC/ESAR data, Int. J. Remote Sens., 18(10), 2105-2124.

Tapley, B. D., S. Bettadpur, J. C. Ries, P. F. Thompson, and M. M. Watkins (2004), GRACE measurements of mass variability in the Earth system, Science, 305(5683), 503-505, doi:10.1126/science.1099192.

Teuling, A. J., and P. A. Troch (2005), Improved understanding of soil moisture variability dynamics, Geophys. Res. Lett., 32, L05404, doi:10.1029/ 2004GL021935.

Teupser, C. (1975), The seismological station of Moxa, Veröff. Zentralinst. Physik d. Erde, 31, 577-584.

Thornthwaite, C. W., and J. R. Mather (1955), The water balance, in Publications in Climatology/Laboratory of Climatology, vol. 8(1), 86 pp., Centerton: Drexel Inst. of Technol., Centerton, N. J.
Torge, W. (1989), Gravimetry, 465 pp., de Gruyter, Berlin.

Troch, P. A., C. Paniconi, and E. E. van Loon (2003), Hillslope-storage Boussinesq model for subsurface flow and variable source areas along complex hillslopes: 1. Formulation and characteristic response, Water Resour. Res., 39(11), 1316, doi:10.1029/2002WR001728.

Van Camp, M., M. Vanclooster, O. Crommen, T. Petermans, K. Verbeeck, B. Meurers, T. van Dam, and A. Dassargues (2006), Hydrogeological investigations at the Membach station, Belgium, and application to correct long periodic gravity variations, J. Geophys. Res., 111, B10403, doi:10.1029/2006JB004405.

Verhoest, N. E. C., P. A. Troch, C. Paniconi, and F. P. de Troch (1998), Mapping basin scale variable source areas from multitemporal remotely sensed observations of soil moisture behavior, Water Resour. Res., 34(12), 3235-3244.

P. W. Bogaart and S. Hasan, Hydrology and Quantitative Water Management Group, Wageningen University, P.O. Box 47, 6700 AA Wageningen, Netherlands. (shaakeel.hasan@wur.nl; shaakeel.hasan@yahoo.com)

C. Kroner, Institute of GeoSciences, Friedrich-Schiller-University, Burgweg 11, Jena, D-07749, Germany.

P. A. Troch, Department of Hydrology and Water Resources, University of Arizona, 1133 E James E. Rogers Way, Tucson, AZ 85721, USA. 